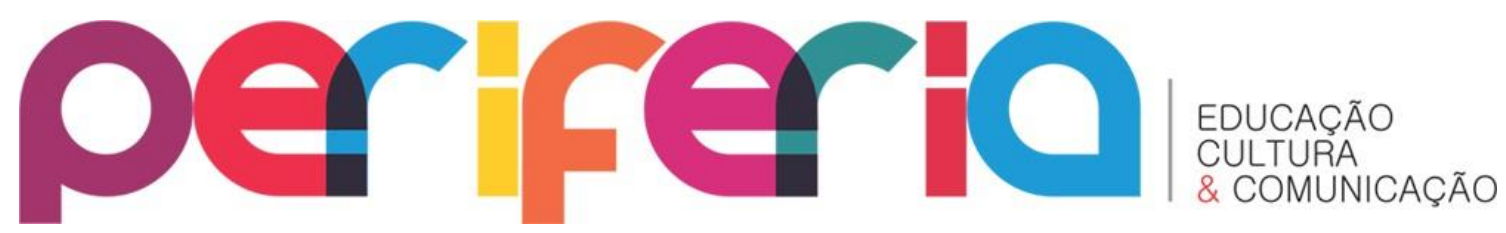

\title{
EDUCAÇÃO SUPERIOR E DEFICIÊNCIA: CENÁRIOS DA INCLUSÃO DE ESTUDANTES COM DEFICIÊNCIA VISUAL NA UNIVERSIDADE
}

Iván Carlos Curioso Vílchez ${ }^{1}$

\section{Resumo}

Há uma falta de pesquisa no campo da educação especial sobre a inclusão de estudantes com deficiência visual no espaço universitário. Este trabalho tem como objetivo identificar as características dos recursos e serviços disponíveis para o atendimento dos alunos com deficiência visual, em uma universidade privada em Lima, Peru. Realizaram-se entrevistas semiestruturadas presenciais, com seis estudantes universitários com deficiência visual, para compreender melhor suas necessidades educativas. Os dados foram transcritos e, depois de uma análise de conteúdo, identificaram-se cinco categorias temáticas. Em um primeiro âmbito, destacam-se as dificuldades da gestão da universidade em relação à adaptação e digitalização dos textos acadêmicos. Em um segundo âmbito, percebe-se a falta de estratégias e técnicas para adequação das tarefas e avaliação pelos professores. Em um terceiro âmbito, menciona-se a carência de formação e capacitação dos funcionários e da comunidade universitária em relação às atitudes sociais para um atendimento adequado a esse grupo. Em um quarto âmbito, realçam-se os problemas de acessibilidade no campus universitário. Finalmente, destacaram-se algumas recomendações para a gestão universitária baseadas no monitoramento da inclusão. Conclui-se que as políticas dessa universidade, no campo da deficiência, ainda estão em construção e devem ser fiscalizadas, com base nas normas legais nacionais e internacionais.

Palavras-chave: educação especial; educação superior; estudantes universitários; deficiência visual; inclusão.

1 Doutor em Educação pela Universidade Estadual Paulista, Marília/São Paulo, Brasil. E-mail: icuriosov@gmail.com; ORCID: https://orcid.org/0000-0002-4812-4630 




\title{
HIGHER EDUCATION AND DISABILITY: INCLUSION OF STUDENTS \\ WITH VISUAL IMPAIRMENT IN THE UNIVERSITY
}

\begin{abstract}
There is a lack of research in the special education field about the inclusion of students with visual impairment studying in the university. This study wants to identify resources and services available for students with visual impairment in a private university located in Lima, Peru. This was a descriptive study research. The researcher performed semi-structured face-to-face interviews. The participants involved were six students with visual impairment admitting in a private university. The following thematic categories were determined after the content analysis: a) difficulties with the management of the university for the adaptation and digitalization of its academic texts, b) lack of strategies and techniques for testing by the teachers, c) insufficiency of training for university employees and the community regarding social attitudes of people with visual impairment, d) problems with accessibility on the university campus, and e) recommendations for university management about inclusion. It was concluded that university policies in the field of disability are still under construction and should be monitored, based on national and international legal norms.
\end{abstract}

Keywords: special education; higher education; university students; visual impairment; inclusion.

\section{EDUCACIÓN SUPERIOR Y DISCAPACIDAD: ESCENARIOS DE INCLUSIÓN DE ESTUDIANTES CON DISCAPACIDAD VISUAL EN LA \\ UNIVERSIDAD}

\section{Resumen}

Existe un vacío de investigación en el campo de la educación especial sobre la inclusión de estudiantes con discapacidad visual en el espacio universitario. Este trabajo tiene como objetivo identificar las características de los recursos y servicios disponibles para la atención de estudiantes con discapacidad visual en una universidad privada de Lima, Perú. Se realizaron entrevistas semiestructuradas presenciales con seis estudiantes universitarios con discapacidad visual para comprender mejor sus necesidades educativas. Se 


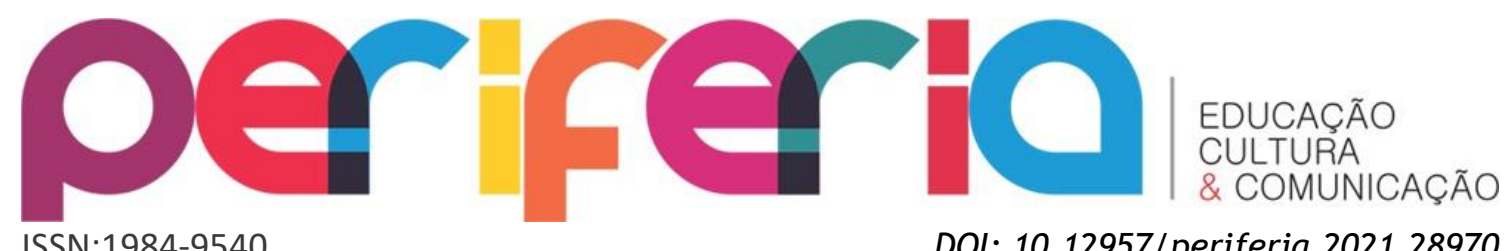

ISSN:1984-9540

DOI: $10.12957 /$ periferia.2021.28970

transcribieron los datos y después de un análisis de contenido se identificaron cinco categorías temáticas. En una primera categoría, se destacan las dificultades de la gestión universitaria en relación a la adaptación y digitalización de textos académicos. En una segunda categoría, faltan estrategias y técnicas para la adecuación de las tareas y la evaluación por parte de los docentes. En una tercera categoría, se hace mención a la falta de formación y capacitación de los empleados y de la comunidad universitaria en cuanto a las actitudes sociales para una adecuada atención a este colectivo. En una cuarta categoría, se enfatizan los problemas de accesibilidad en el campus universitario. Finalmente, se indicaron algunas recomendaciones para la gestión universitaria basada en el seguimiento de la inclusión. Se concluye que las políticas de la universidad, en el campo de la discapacidad, aún se encuentran en construcción y deben ser monitoreadas, en base a los estándares legales nacionales e internacionales.

Palabras clave: educación especial; educación universitaria; estudiantes universitarios; discapacidad visual; inclusión.

\section{INTRODUÇÃO}

O espaço universitário, como outros contextos educativos, deve ser um lugar que disponibilize, em igualdade de oportunidades, diferentes serviços e recursos adaptados para oferecer um atendimento de qualidade para os estudantes com deficiência visual (SALLÁN; MORENO, 2013; GROSS, 2014; RAMÍREZ, 2015). Não obstante, a universidade tem condições educacionais que carecem de uma assistência adequada para seu ensino, aprendizagem e avaliação de pessoas com esse tipo de condição (PEREIRA et al., 2016; PÉREZJORGE et al., 2016), bem como os critérios da acessibilidade e desenho universal ainda por melhorar (STUPP, 2002; FUENTES, 2003; PASTOR, 2005; MANZINI, 2006b; PEREIRA, 2008; ZHOU et al., 2011; MANZINI; CORRÊA, 2014).

$A$ isso se agrega um ambiente social discriminatório e excludente, onde surgem preconceitos e estigmas sociais, no qual se considera que uma pessoa com deficiência visual não pode ser capaz de ingressar no ensino superior e atingir os mesmos objetivos de estudantes considerados como regulares ou “normais" (MAGALHÃES; RUIZ, 2011; ESTÁCIO; ALMEIDA, 2016).

Em outros casos, esse tipo de carências e dificuldades faz que os estudantes com deficiência visual desistam ou se afastem do ensino superior 


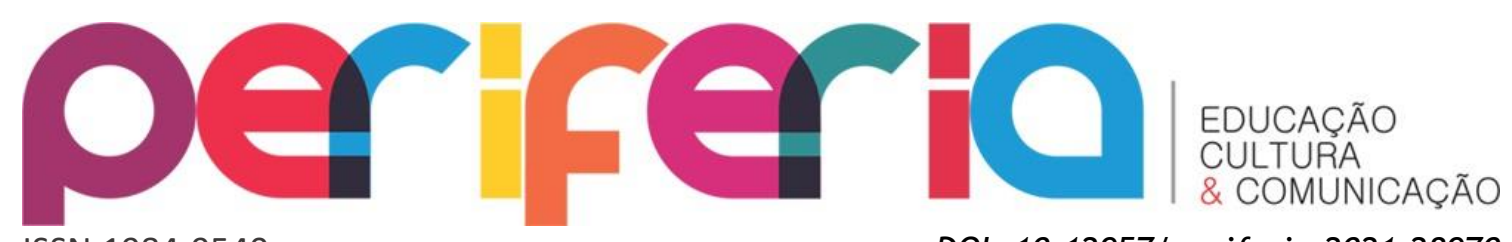

ISSN:1984-9540

DOI: $10.12957 /$ periferia.2021.28970

(ROCHA; MIRANDA, 2009). Nessa direção, o processo da inclusão requer uma convivência tolerante e consciente das necessidades e adequações de acessibilidade para esse grupo-alvo por parte dos diretores, funcionários, professores e comunidade em geral da universidade (ANACHE; ROVETTO; OLIVEIRA, 2014; BRASIL, 2015).

Além disso, a gestão do ensino superior e seus professores devem contar com as estratégias pedagógicas adequadas, para propor uma metodologia de ensino eficaz e eficiente, com adaptações curriculares para suas diversas áreas do conhecimento (SALAZAR; SÁNCHEZ, 2011; CAMARGO, 2012; CAMARGO; NARDI, 2013; REGIANI; MÓL, 2013; VIVEIROS; CAMARGO, 2014; MENDES; BASTOS, 2016), assim como o acesso e uso das tecnologias da informação e comunicação, que são recursos de apoio de vital importância para o ensino e aprendizagem dos estudantes com deficiência visual (ONCE, 2011; YUE-TING; MORASH, 2014).

Dessa forma, para o propósito deste trabalho, analisaremos as vozes dos próprios estudantes com deficiência visual, que estão incluídos em uma das universidades privadas do Peru, tomando em consideração os recursos e serviços que eles recebem no ambiente educativo.

No Peru, há lei geral para pessoas com deficiência (Lei n. 29.973, aprovada em 14 de junho de 2012), que destaca, no artigo 38, que a universidade e outras instituições de ensino técnico superior, sejam públicas ou privadas, devem incorporar em seus procedimentos de vestibular os meios de comunicação, equipamentos tecnológicos e informações acessíveis para pessoas com essa condição. Essas instituições devem fazer os ajustes e adaptações necessários para atender a tais demandas. Assim, essas instituições de ensino superior devem reservar $5 \%$ das suas vagas para candidatos com deficiência, os quais devem ser identificados através de seu cartão de deficiência nacional, proporcionado e validado pelo Conselho Nacional sobre Deficiência (CONADIS) desse país.

Complementarmente, o artigo 25 estabelece que as universidades, entre outras instituições de ensino técnico superior, deveriam oferecer cursos e disciplinas sobre acessibilidade e desenho universal em seus currículos. 


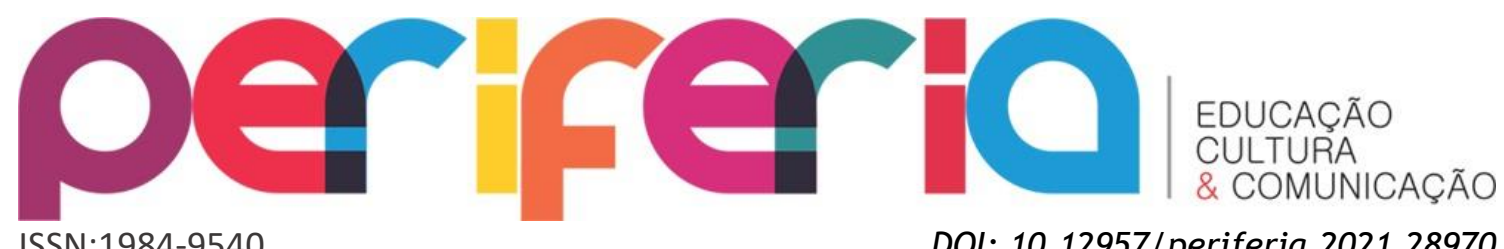

ISSN:1984-9540

DOI: $10.12957 /$ periferia.2021.28970 Nesse aspecto, o artigo 39 salienta que essas instituições devem incluir no plano de ensino das diferentes carreiras, por exemplo, engenharia, ciências sociais, ciências da saúde, humanidades, dentre outros, a temática sobre deficiência. Pode-se destacar o artigo 40, que estabelece que as bibliotecas do ensino técnico e superior devem ter suas instalações acessíveis e com materiais adaptados, dependendo do tipo de deficiência. No caso das pessoas com deficiência visual, por exemplo, material no sistema Braille e audiolivros.

Portanto, existem políticas públicas e sociais com ênfase na área da deficiência visual e que são de suma relevância para refletir a inclusão no contexto universitário peruano.

\section{METODOLOGIA}

Trata-se de um estudo com uma abordagem qualitativa. Esse tipo de estudo tem como finalidade pesquisar e interpretar as percepções e ações dos indivíduos e outros fenômenos sociais (MERRIAM; TISDELL, 2015). Para isso, foram feitas entrevistas presenciais semiestruturadas, cuja finalidade foi identificar e descrever as características dos recursos e serviços disponíveis para o atendimento aos alunos com deficiência visual, dentro de uma universidade privada em Lima, Peru. Essas entrevistas foram individuais e foram levadas em consideração as condições éticas desse país como o Termo de Consentimento Livre e Esclarecido. Por razões de confidencialidade, permanecem no anonimato as identidades e quaisquer outras informações dos nossos participantes e da instituição (COHEN; MANION; MORRISON, 2011).

Os participantes da pesquisa têm entre 20 e 48 anos. A média de idade é de 27,5 anos. No grupo em questão, são quatro homens e duas mulheres. Três deles têm cegueira completa congênita; dois têm cegueira completa por causa de doenças; e apenas um estudante tem baixa visão. Do grupo de estudantes entrevistados com deficiência visual, cinco estão realizando estudos de graduação e um deles, pós-graduação.

As entrevistas foram transcritas, organizadas e sistematizadas por meio de análise de conteúdo e logo depois por categorias temáticas (MANZINI, 




2006a; BARDIN, 2010; URQUHART, 2012). No presente texto, apresentam-se alguns trechos de seus diálogos, indicados com a letra “E”. Esse tipo de letra servirá para designar os estudantes com deficiência visual.

Após uma análise mais aprofundada do conteúdo dos entrevistados, foram encontradas e sistematizadas cinco categorias temáticas, a destacar: 1) dificuldades da gestão da universidade em relação à adaptação e digitalização dos textos acadêmicos; 2) falta de estratégias e técnicas para adequação das tarefas e avaliação pelos professores; 3 ) carência de formação e capacitação dos funcionários e da comunidade universitária em relação às atitudes sociais para um atendimento adequado a esse grupo; 4) Problemas de acessibilidade no campus universitário; e, finalmente, 5) recomendações para a gestão universitária baseadas no monitoramento da inclusão.

\section{RESULTADOS E DISCUSSÃO}

1) Dificuldades da gestão da universidade em relação à adaptação e digitalização dos textos acadêmicos

Para nossos participantes com deficiência visual, ingressar em uma universidade foi um dos primeiros objetivos após deixar a escola. Logo depois de ingressar nessa instituição, eles tinham grande preocupação sobre como seria o tipo de atendimento e adequação dos recursos e serviços educacionais para pessoas com sua condição. Em um primeiro momento, os funcionários, em geral, ficaram surpresos sobre como foram admitidos no ensino superior. Ademais, as diversas áreas da secretaria e coordenação da universidade demonstraram preocupação em lhes oferecer, segundo suas possibilidades, o melhor atendimento possível.

Os estudantes, por sua própria iniciativa, reuniram-se com 0 secretariado e a coordenação para conhecer mais como seria sua situação dentro da universidade. Eles foram informados que podiam dirigir-se a um Serviço de Atenção para Pessoas com Deficiência, dentro da biblioteca principal da universidade, e que isso poderia ajudá-los em suas necessidades 


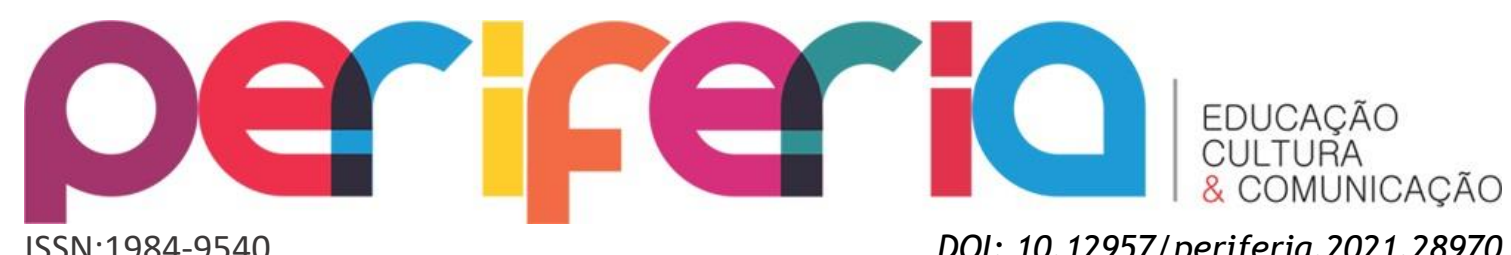

ISSN:1984-9540

DOI: $10.12957 /$ periferia. 2021.28970 educativas. Essa unidade é a responsável pela adaptação e digitalização dos textos acadêmicos, ou seja, por converter os textos impressos das disciplinas em arquivos de texto, por exemplo, em Word e PDF, para que eles possam ser usados por leitores de tela, como o Job Access With Speech (JAWS)2.

Os participantes destacam que existe um imenso apoio proporcionado pela unidade, porém, certas limitações para cobrir suas necessidades. Por exemplo, enfatizou-se que nem todas as disciplinas possuem um plano de ensino padronizado, no qual estejam detalhadas as leituras obrigatórias, que são objeto de avaliação pelo professor. Para eles, isso é uma grande dificuldade, pois relataram que o serviço da biblioteca não tinha tempo suficiente para digitalizar todas essas leituras com antecedência. Isso se devia à falta de recursos humanos necessários ou, em outros casos, porque a maior parte da equipe era de estagiários, que desconheciam como adaptar os materiais, e de outros que demoravam, pois estavam aprendendo as funções de digitalização.

Ademais, os scanners usados para essa finalidade se estragavam constantemente, por causa do tempo excessivo em que foram utilizados para o processo de digitalização dos textos. Outro aspecto a ressaltar é que, na maioria das vezes, os funcionários da biblioteca priorizavam as leituras obrigatórias e não tinham tempo para digitalizar as leituras eletivas, que os estudantes com deficiência visual podiam precisar para depois ou que simplesmente queriam ler como passatempo ou para complementar seus estudos.

Com relação a essas questões, os estudantes recomendam que a biblioteca da universidade possa coordenar, de melhor maneira, com os professores, para que possuam e enviem à ela um plano de ensino estruturado e detalhado das avaliações. Por exemplo, uma descrição das leituras obrigatórias a serem utilizadas, com um cronograma que especifique as datas exatas das suas avaliações. Isso poderia ajudar à equipe de digitalização da biblioteca a ter melhor noção da demanda desse tipo de trabalho. Também se

\footnotetext{
2 Disponível em: <http://www.freedomscientific.com/Products/Blindness/JAWS>. Acesso em 25 jan. 2017.
} 


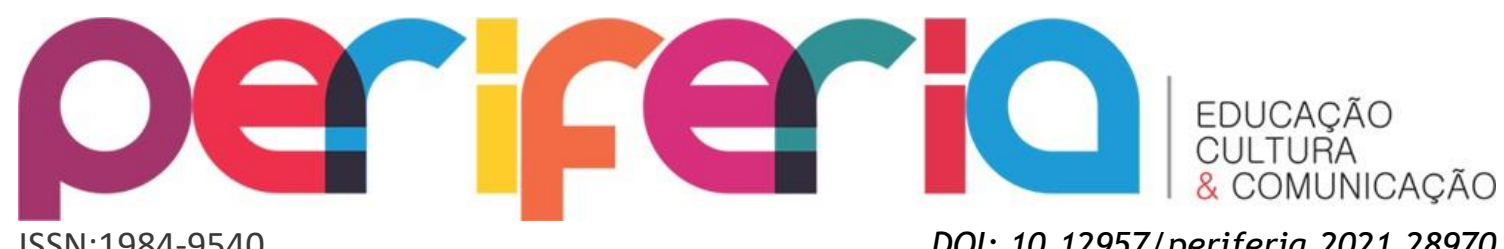

sugeriu que os arquivos que são digitalizados poderiam ser convertidos em áudio, para que possam ser usados em seu reprodutor de som pessoal. Dessa forma, os entrevistados ressaltaram programas como TextAloud ${ }^{3}$, que pode realizar essas adaptações. Esses arquivos poderiam ser armazenados numa base de dados e poderiam estar separados por disciplinas, docentes e anos, para que, no futuro, outros estudantes com essa condição possam utilizá-los. Um dos participantes assinala:

No meu ponto de vista, é irritante que tenha alguém lendo para mim, não vou estar com uma pessoa sempre ao meu lado, ficaria chateado [...]. O que faz o serviço da biblioteca da universidade é de grande ajuda para meus estudos [...]. A biblioteca digitaliza as leituras que eu preciso em minhas disciplinas [...]. Talvez uma das dificuldades que se tem com isso é que nem todo mundo tem o tempo suficiente para corrigir os documentos que eu preciso, isso me atrasa em minhas atividades [...]. Outra desvantagem que eu tenho é que o professor na última hora resolve avaliar os estudantes e fala que daqui a dois dias temos uma prova com base nessa leitura, no entanto, esse texto não está digitalizado, e isso me prejudica nos meus estudos [...]. (E5, estudante universitário com deficiência visual)

Cabe ressaltar que os estudantes com deficiência visual entrevistados têm conhecimento e utilizam o leitor de tela JAWS, que permite traduzir o conteúdo do computador no sintetizador de voz. Esse programa está instalado em alguns dos computadores da biblioteca principal da universidade, para que possam ser usados livremente, principalmente, na pesquisa bibliográfica.

Enquanto isso, os estudantes entrevistados têm seu próprio computador e destacam sua preferência em usá-lo dentro da universidade, seja pela privacidade e mobilidade para poder deslocar-se em qualquer lugar e para levá-lo para a sala de aula. Complementarmente, esses estudantes também utilizam o gravador digital. No entanto, dois estudantes salientaram que deveriam realizar minicursos ou oficinas de extensão, feitos por especialistas e outros profissionais, para melhorar ainda mais e potencializar o uso da

\footnotetext{
${ }^{3}$ Disponível em: <www.nextup.com>. Acesso em 20 jan. 2017.
} 


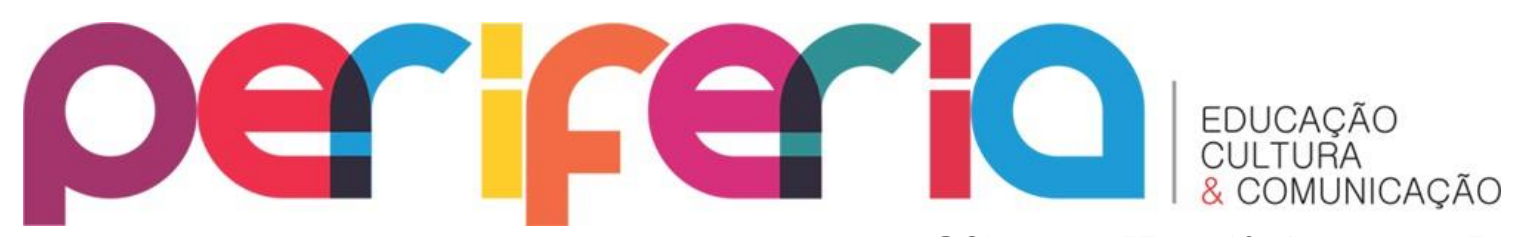

ISSN:1984-9540

DOI: $10.12957 /$ periferia.2021.28970

tecnologia assistiva para pessoas com deficiência visual dentro da universidade.

Todos os entrevistados assinalaram que tinham algum tipo de conhecimento do sistema Braille, para ler e escrever com o uso da reglete e punção, mas, infelizmente, enfatizaram que não tinha uma utilidade eficaz na universidade, porque as pessoas não sabem como usar esse sistema. Além disso, a universidade não tinha impressoras com essas características, assim como recursos humanos e econômicos que pudessem investir em sua produção. Apenas identificaram o sistema Braille nos números e letras dos elevadores da universidade. Segundos os participantes, até o momento, em sua universidade, não se têm placas de sinalização feitas em Braille.

Os estudantes mostraram seu desconforto ao usar textos impressos em Braille, pelo volume que ocupam e pelo incômodo de guardá-los na sua mochila pessoal, além de reconhecer a dificuldade para se deslocar a outros ambientes da universidade com esse tipo de textos. Frente a isso, salientou-se a utilidade do notebook, telefone (smartphone) e tablet, como recursos de informação e comunicação, interação social e aprendizagem de grande valor para seus estudos.

Como dito anteriormente, sugere-se que, nas universidades, possa existir uma diversidade de equipamentos tradicionais e atuais, sem ser tão sofisticados, para o atendimento especializado a estudantes com deficiência visual, e que possam ser usados segundo sua relevância e habilidades (ROCHA; MIRANDA, 2009).

\section{2) Falta de estratégias e técnicas para adequação das tarefas e avaliação pelos professores}

Antes de aprofundar nesse tema, curiosamente, os alunos com deficiência visual entrevistados recordaram suas provas de vestibular para entrar na universidade. Eles comentaram que o exame foi realizado em uma sala de aula, isolada dos outros estudantes. Foram acompanhados com um assistente que leu as perguntas e marcavam as respostas para eles. Estas 


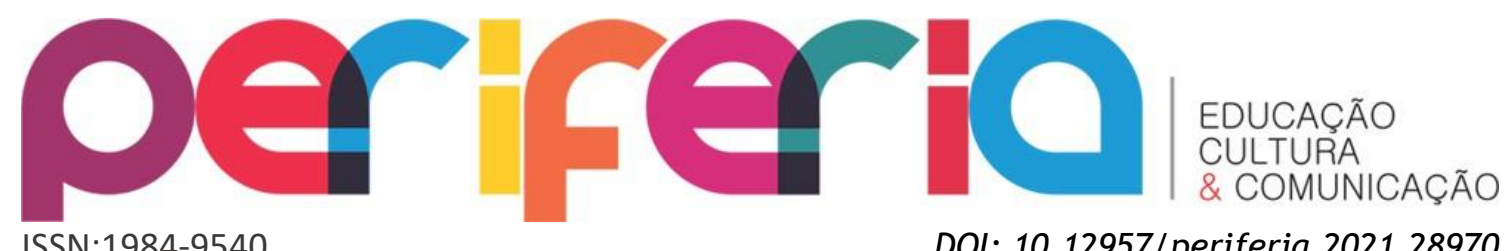

provas foram de questões objetivas. O tempo para fazer a prova foi igual ao de qualquer aluno que não tivesse algum tipo de deficiência visual. No entanto, sugeriram considerar um tempo adicional, já que, muitas vezes os auxiliares tinham que repetir as perguntas para que eles entendessem seu conteúdo e decorassem mentalmente as respostas de múltipla escolha, para darem a resposta final. Em média, eles lembraram que se tinham quatro opções na prova, e um dos estudantes sugeriu que se adapte essa prova de múltipla escolha para três opções, uma vez que isso permitiria compreender e reter o conteúdo de uma melhor maneira.

Ressaltou-se, ademais que a pessoa, que os ajudou na prova do vestibular não era necessariamente a mais oportuna e preparada, porque lia as perguntas para eles devagar, fazendo-os sentirem-se bastante desconfortáveis. Alguns tinham medo ou timidez para questionar tais ações. Quatro dos estudantes com deficiência visual sugeriram que esse tipo de assistência os deixou sem autonomia.

Além disso, recomendaram que, para futuros alunos com deficiência visual que desejem ingressar na universidade, pode-se adequar os vestibulares para outros formatos. Assim, o estudante pode ter a opção de decidir qual seria a melhor maneira de ser avaliado. Nesse caso, quatro dos alunos enfatizaram que esse tipo de prova poderia ser realizado em um computador, com o uso do leitor de tela JAWS. Aqui, ressaltaram que existem outros tipos de leitores de tela que podem ser de acesso livre, como o NonVisual Desktop Access (NVDA) ${ }^{4}$. Embora considerem o JAWS como o mais prático, com as suas funções de comando e interação mais agradáveis, diferentemente do leitor de tela NVDA. Apenas um aluno assinalou que a prova poderia ser no sistema Braille ou oralmente.

Como já colocado, esses alunos com deficiência visual agregam que as características do vestibular estão longe de seus procedimentos de provas e práticas atuais. Afirmam que, na maioria das avaliações, o professor não está presente e se conta com um auxiliar/assistente, que os leva a uma sala

\footnotetext{
${ }^{4}$ Disponível em: <www.nvaccess.org>. Acesso em 20 jan. 2017.
} 


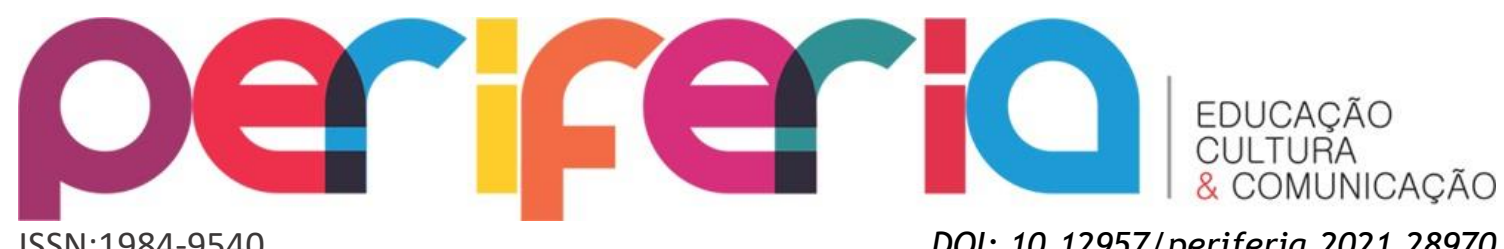

adjacente e thes fornece um computador que pertence à universidade. Nesse computador, o assistente coloca um pendrive, com o arquivo que contém as questões de prova, na maioria das vezes, perguntas abertas, para que o estudante escreva e responda logo em seguida. Para isso, os alunos ativam o leitor de tela JAWS e realizam a prova no arquivo de Word.

Após completar suas respostas, o assistente imprime a prova, para entregá-la ao professor. Esse tipo de modalidade é muito mais acessível e independente para os estudantes, mas ela não remove o anonimato do estudante. Aliás, nessa universidade, as provas são de caráter anônimo para os estudantes, em outras palavras, não se sabe de quem é a prova para dar um critério de confidencialidade e de não conflito de interesses entre o estudante e o professor. Imprimir sua prova para esse grupo-alvo delataria que foi feita por um deles. Um dos participantes destaca:

Seria importante que os professores tivessem um conhecimento especializado para adaptar as perguntas, as provas em geral. Muitos professores fazem bastantes perguntas, para que nós respondamos às provas. Eles têm que considerar que, dependendo do domínio do computador dos estudantes cegos, alguns de nós podem demandar mais tempo para escrever as respostas [...]. Às vezes, tenho que escrever rápido e não dou conta de completar minhas respostas e revisar que minhas ideias estejam bem escritas no computador, pois o tempo que tenho já deu para finalizar a prova [...]. (E1, estudante universitário com deficiência visual)

Entretanto, às vezes, tendo em conta o critério do professor, eles também podem fazer o exame de forma oral. Na maioria dos casos, esse tipo de modalidade ocorre em cursos de ciências como matemática e estatística, nos quais os gráficos ou tabelas são muito difíceis de usar e ler com o leitor de tela JAWS, porque esse programa não pode reconhecer de maneira certa as imagens e ilustrações. Ele faz uma leitura linear. Porém, dois dos entrevistados sugeriram que pode-se adaptar essas tabelas ou gráficos em Braille ou em alto relevo, para que possam ser utilizados através da leitura manual. Aqui, seria oportuno mencionar que recursos como alto relevo e materiais tridimensionais ajudam os alunos com deficiência visual a 


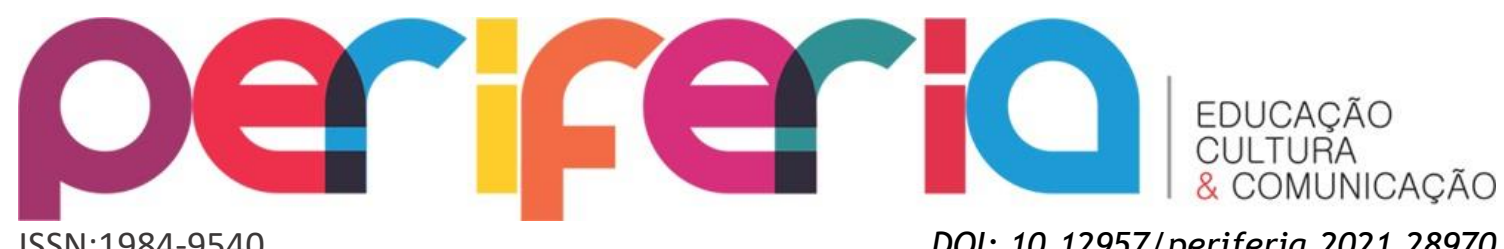

ISSN:1984-9540

DOI: $10.12957 /$ periferia.2021.28970 aprenderem conceitos de ciências exatas, como física e matemática. Esses formatos poderiam ser adaptados pelos professores e especialistas dessas áreas (CAMARGO, 2012; CAMARGO; NARDI, 2013; VIVEIROS; CAMARGO, 2014).

\section{3) Carência de formação e capacitação dos funcionários e da comunidade} universitária em relação às atitudes sociais para um atendimento adequado a esse grupo

Entre os desafios que são destacados pelos estudantes entrevistados com deficiência visual, evidencia-se que, muitas vezes, os professores esquecem que eles estão na sala de aula e se comunicam com sua turma como se eles pudessem enxergar. Eles quase sempre se sentam nas primeiras fileiras da sala de aula e perto da porta de saída para qualquer eventualidade ou emergência. Para eles, os professores em geral carecem de um tipo de treinamento, vontade e motivação para adequar seu sistema de ensino para estudantes com sua condição. Em certas ocasiões, têm medo de reclamar com seus professores, porque acreditam que podem ser reprovados na disciplina.

Nesse sentido, as principais dificuldades surgem em matérias de ciências ou nas que contêm muitos gráficos e ilustrações, principalmente, no caso de exercícios práticos, quando os professores usam a lousa ou, em outros casos, apresentam imagens no projetor ou datashow. Alguns, por conta própria, pedem ajuda a algum amigo que está perto, para que os auxilie em sua compreensão ou depois solicitam a impressão desses exercícios e pedem que alguém ou algum colega possa interpretá-los. Às vezes, seus companheiros de aula podem ajudar, mas eles preferem não fazer isso cotidianamente, para não parecerem tão chatos. Um dos participantes menciona que:

Os problemas de adaptação que tenho na sala de aula são na maior parte das disciplinas que têm qualquer imagem das matérias de ciências. 0 professor desenvolve exercícios no quadro e não vejo nada. Ele realiza gráficos, mas não fala do que se trata quando vai desenhando. Seria bom que o professor explicasse todos os valores numéricos para compreendê-lo [...]. Os professores não estão preparados para ensinar a uma pessoa com deficiência visual [...]. Eu tenho 


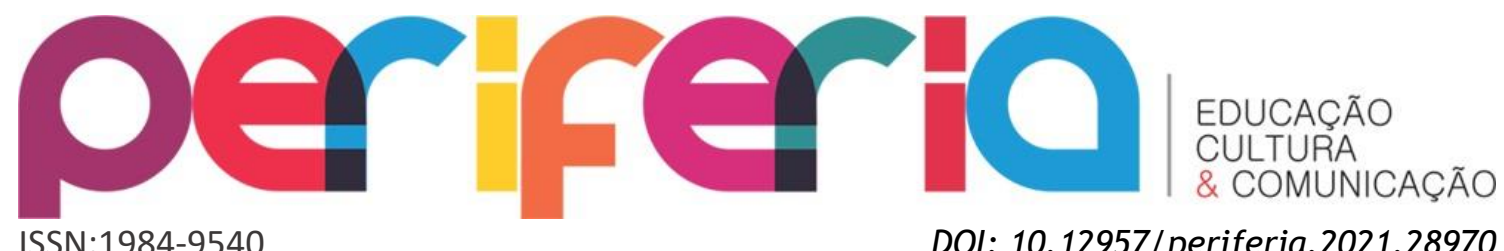

que pedir ajuda a meu amigo, fora da sala de aula, para que me possa dizer o que o professor fez no quadro. Isso me faz perder meu tempo com outra pessoa para pedir sua ajuda [...]. (E2, estudante universitário com deficiência visual)

A esse respeito, os estudantes com deficiência visual entrevistados têm conhecimento de que existem técnicas de audiodescrição, que podem ser utilizadas pelos professores de forma inovadora, como ferramentas para sua aprendizagem (MOTTA; FILHO, 2010; RIOS et al., 2016a). Por exemplo, esses recursos poderiam ser entregues em $C D$, colocados na plataforma virtual da disciplina ou encaminhados a seus e-mails, para que possam compreender melhor o conteúdo proposto pelo professor em seus slides ou apresentações.

Além disso, podem-se fazer também imagens com impressões em 3D, tomando como base fotografias ou outras ilustrações que possam ser adaptados em alto relevo e que, assim, possam explorar outros campos sensoriais além da visão (ARAUJO; SANTOS, 2015; MINEIRO; ALMEIDA; LÉLIS, 2015).

Por outra parte, destacaram a falta de cursos de graduação e pósgraduação para abordar o processo da educação inclusiva e especial de pessoas com deficiência no nível do ensino superior. No entanto, há algumas iniciativas de alguns alunos da Faculdade de Ciências Sociais e Humanidades que tratam desse tema em algumas feiras de responsabilidade social na universidade. Há também propostas no curso de Direito, que realizam disciplinas de extensão e assessoria jurídica, de forma voluntária, para abordar o tema do respeito aos direitos das pessoas com deficiência.

Nessa lógica, os alunos com deficiência visual concordaram que o serviço da biblioteca poderia ser uma unidade mais abrangente e ter uma maior presença, com o objetivo de realizar treinamento e consultoria com profissionais especializados ou através de outras organizações de apoio na educação especial. Isso seria de muito valor para a formação dos professores que tenham alunos com deficiência visual em suas aulas e para a comunidade universitária em geral. 


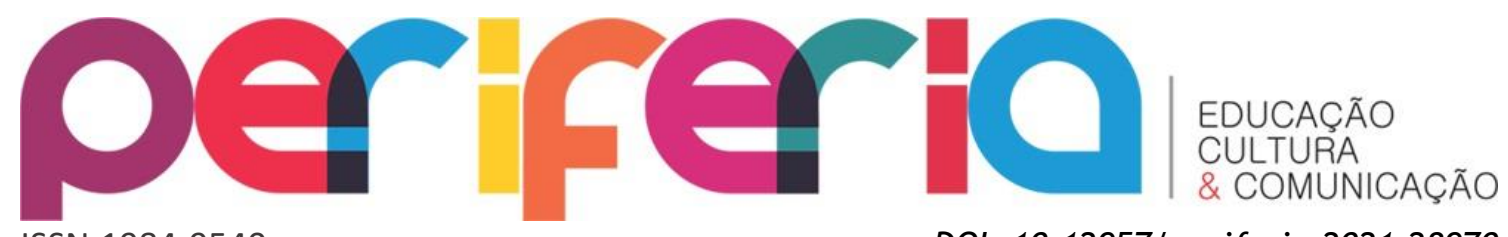

ISSN:1984-9540

DOI: $10.12957 /$ periferia.2021.28970

Dessa maneira, os entrevistados apontam que o fenômeno da discriminação e da exclusão pela sua condição é quase sempre causado pela falta de informação e de conscientização do ambiente social, que desconhece suas necessidades (DINIZ; BARBOSA; SANTOS, 2009).

\section{4) Problemas de acessibilidade no campus universitário}

Nesse aspecto, destacaram-se algumas inadequações de acessibilidade em relação aos recursos tecnológicos nos diferentes laboratórios de informática na universidade, onde nem todos os computadores têm algum tipo de leitor de tela. Desse modo, sugeriram que esses laboratórios possam contar, pelo menos, com alguma licença para seu uso pessoal, seja de uso gratuito ou com custo.

Muitas vezes, preferem trazer seu computador pessoal para fins de trabalhos acadêmicos e para ler com o leitor de tela, porém, têm medo de que possa perder-se ou que, no deslocamento de suas casas até a universidade, possam ser roubados, considerando que a maioria vem de bairros afastados do seu centro educativo.

Com relação ao uso do e-mail da universidade, apontam que é acessível, mas que a página web e as plataformas virtuais (por exemplo, de ensino a distância) da universidade com o leitor de tela JAWS travam ou dão uma parada. Isso ocorre, porque esse tipo de conteúdo faz uso de linguagens de programação com muito flash, assim como apresenta demasiadas ilustrações, animações, imagens ou gráficos, que são inacessíveis e interpretados pelo leitor de tela. Seria adequado avaliar se a acessibilidade com o uso do leitor de tela, nos websites, nas plataformas virtuais u outros recursos educacionais oferecidos pela universidade, é ou não de utilidade para as pessoas com deficiência visual (ONCE, 2011; RIOS et al., 2016b). Um dos participantes relata que:

A universidade não só deve proporcionar a possibilidade de ingressar nela, mas também deve dar todas as oportunidades até que estejamos formados [...]. Deveria nos dar todos os 


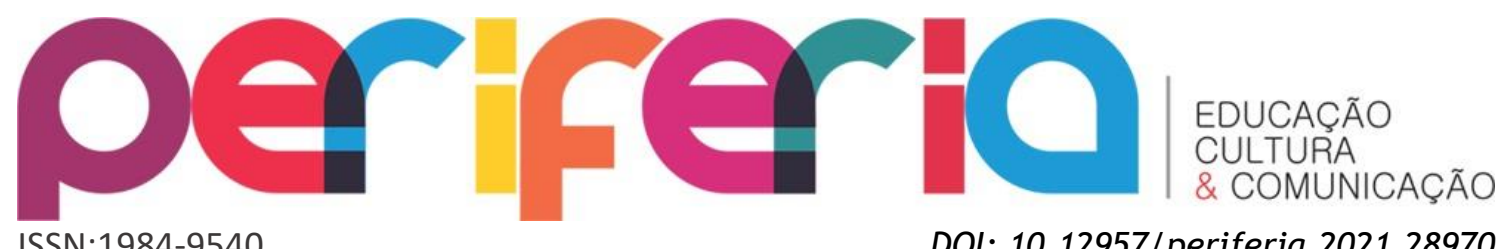

recursos acessíveis para nós [...]. O fundamental da inclusão do estudante cego não é só o bom comportamento das pessoas, mas também da disposição do ambiente físico, da infraestrutura de onde nós estamos, que eu possa guiar-me com minha bengala, que tenha piso podotátil, que o chão não tenha inclinações ou buracos que possam me machucar [...]. (E4, estudante universitário com deficiência visual)

De modo particular, o estudante que estava na pós-graduação sugeriu que o website da universidade e seus recursos digitais poderiam contar com um botão acessível, com o qual se possa reproduzir de modo automático algum tipo de áudio de voz. Para isso, manifestou programas como ReadSpeaker $^{5}$, os quais digitalizam o conteúdo dos textos a voz das websites, artigos, dentre outros documentos ou publicações que sejam acessíveis na Internet.

Por outra parte, com respeito aos problemas de acessibilidade física, notaram que, nos diferentes lugares da universidade, há espaços arquitetônicos bastante abertos, onde eles podem movimentar-se livremente, embora prefiram ir a lugares diferentes, com ajuda de algum amigo que possa orientá-los.

Sugerem que as salas de aula sejam, em sua maioria, no primeiro andar, levando em conta o tempo demandado para ir até prédios mais altos. Apontase também, em geral, a falta de piso podotátil, para se localizar ou movimentar de forma mais eficiente no campus universitário por meio da bengala.

Também foi sugerido um elevador para a biblioteca principal da universidade, que, atualmente, tem três andares. A esse respeito, observouse que os elevadores, em sua maioria, têm sistema Braille, embora faltem sinais sonoros que podem orientá-los melhor. Três estudantes destacaram que - elevador que usam em seus respectivos prédios de aula têm, ocasionalmente, uma voz robótica, mas que, em determinados momentos, se desconfigura(m) por alguma(s) pessoa(s), pois acredita(m) que pode parecer chato para outros estudantes.

\footnotetext{
${ }^{5}$ Disponível em: <www.readspeaker.com>. Acesso em 18 jan. 2017.
} 


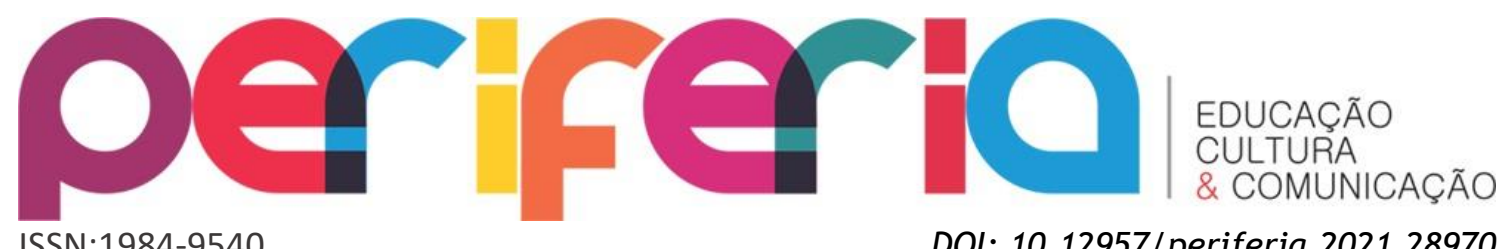

ISSN:1984-9540

DOI: $10.12957 /$ periferia.2021.28970

Assim, é importante notar que essa universidade deve monitorar os critérios de acessibilidade e desenho universal propostos pelos outros países, em nível internacional (MANZINI, 2006b; MANZINI; CORRÊA, 2014; BRASIL, 2015), com a finalidade de que tais ajustes lhes permitam ter uma maior autonomia e independência em seu centro de ensino superior.

\section{5) Recomendações para a gestão universitária baseadas no monitoramento da inclusão}

Nesse ponto, os estudantes com deficiência visual entrevistados assinalaram que a universidade poderia complementar e melhorar ainda mais seu tipo de atenção para esse grupo-alvo, com profissionais e organizações nacionais de educação especial, como, por exemplo, o Serviço de Apoio e Orientação à Necessidades Educativas Especiais desse país. Esse tipo de serviço tem foco no trabalho na educação especial e inclusiva, que se estende ao nível de ensino inicial, fundamental e médio (MINEDU, 2012). Por exemplo, alguns autores concordam que o espaço universitário deveria dialogar e aprender as estratégias e técnicas de ensino/aprendizagem com especialistas de outras áreas e instituições, que possam reforçar um atendimento educacional especializado para esse grupo-alvo (ANACHE; ROVETTO; OLIVEIRA, 2014). Além disso, seria interessante que pudessem conhecer experiências de outros países sobre a inclusão de estudantes com deficiência visual na educação superior (SALLÁN; MORENO, 2013; ÁVILA; SALLÁN, 2016). A ideia seria aprender e intercambiar sugestões de um modelo educativo mais inclusivo e abrangente, que possa potencializar suas condições de vida pessoal, educacional e social na universidade.

Os entrevistados com deficiência visual estão cientes de que são um grupo minoritário na universidade. Sua eficaz inclusão é também uma questão de despesas financeiras, que depende do orçamento da instituição. De modo particular, sugeriram que o governo e/ou a universidade deveriam incentivar e auxiliá-los com algum tipo de bolsa de estudos, considerando que têm maiores necessidades e demandas acadêmicas. Ressalta-se, assim, que o 




ISSN:1984-9540

DOI: $10.12957 /$ periferia.2021.28970

parcial sucesso dos estudantes com deficiência visual na universidade dependerá também da gestão universitária, que possa monitorar e oferecer um acompanhamento especializado para eles ou elas (MENDES; BASTOS, 2016), assim como das altas hierarquias de poder que fomentam politicas públicas e sociais para seu processo de inclusão na educação superior (PEREIRA et al., 2016).

Ressaltou-se também ações que facilitam estratégias de marketing e publicidade sobre a inclusão desse grupo de estudantes, pois os entrevistados sabem de colegas com sua condição que desconhecem os tipos de recursos e adaptações que pode oferecer essa universidade em seus estudos. Ademais, destacou-se a existência de um cadastro de pessoas com deficiência visual, para que, adiante, possam formar um grupo ou uma associação de estudantes, que zelem por seus direitos educacionais na universidade. Em outros termos, um dos participantes menciona que:

A maior dificuldade é que a universidade nunca imaginou que uma pessoa cega pudesse entrar em um lugar como esse. Agora que sabe que estamos ingressando e estudando aqui, gradualmente procura nos proporcionar um melhor atendimento. [...]. Eu acho também que a universidade não pode dar-nos tudo, depende também de nós, eu veio que falta o tema de agrupações dos mesmos estudantes com deficiência, não existe uma parceria. Por outra parte, nas minhas aulas falta mais pesquisa, estou entediado que a maioria faça temas empresariais e que não abordem o tema da deficiência de uma maneira mais pública e social, eu sei que é um tema delicado, mas como você pensa melhorar um tema se você não aborda ele $[. .$.$] . (E3, estudante universitário com deficiência visual)$

Por último, recomendou-se que a área de avaliações do vestibular e sua coordenação, dentre outras unidades, devem contar com uma adequada gestão e sistematização dos estudantes com deficiência que ingressam na universidade. Finalmente, sugeriu-se o acompanhamento de seus estágios e formas de inclusão laboral, durante e logo após seus estudos universitários, cujos procedimentos são ainda mais desafiantes. 


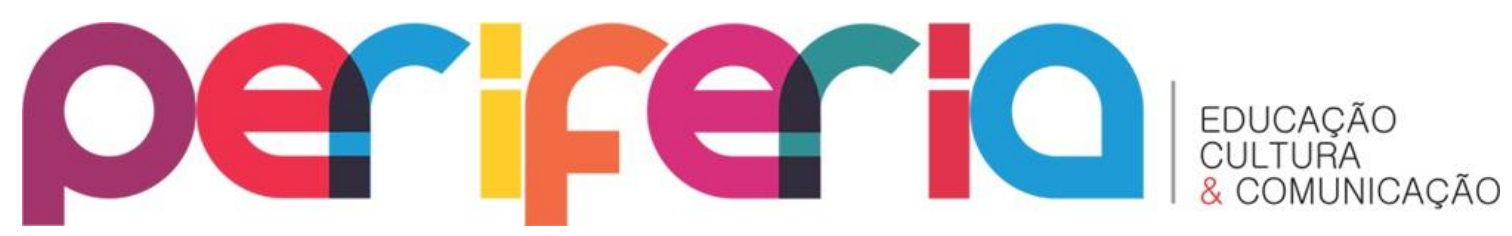

O espaço universitário deve ser um lugar de convivência para estudantes com ou sem deficiência. No caso de estudantes com deficiência visual no ensino superior, devem-se considerar metodologias e currículos mais flexíveis, enfatizando suas necessidades educativas particulares. A proposta é proporcionar adaptações de qualidade de recursos e serviços, dentro e fora da sala de aula, que sejam de interesse e utilidade para o estudante com essa condição.

Além disso, a universidade poderia oferecer serviços ou cursos de formação sobre atendimento especializado a alunos com deficiência voltados para a comunidade educacional em geral (professores, funcionários, estudantes com ou sem deficiência, entre outros). No entanto, pode-se propor a existência de uma coordenação mais estreita com as diversas áreas da universidade, que possa sistematizar como está se dando sua inclusão. Nessa perspectiva, é de suma importância refletir ou recomendar que se possam ter instâncias e atores sociais, dentro da universidade ou fora dela, que supervisionem e sejam vigilantes para dar continuidade às diversas práticas e estratégias de inclusão na educação superior desse grupo-alvo.

Dessa forma, é importante elaborar trabalhos que evidenciem dados empíricos (qualitativos e quantitativos), a fim de apontar novas linhas de ação, segundo as demandas e exigências de estudantes com deficiência visual na universidade, para um ensino de qualidade que promova o respeito a sua diversidade.

\section{REFERÊNCIAS}

ANACHE, A.; ROVETTO, S.; OLIVEIRA, R. Desafios da implantação do atendimento educacional especializado no Ensino Superior. Revista Educação Especial, Santa Maria, v. 27, n. 49, p. 299-312, 2014.

ARAUJO, M.; SANTOS, D. Fotografia tátil: desenvolvimento de modelos táteis a partir de fotografias com a utilização de impressora 3D. Revista Brasileira de Design da Informação, São Paulo, v. 12, n. 1, p. 62-76, 2015. 


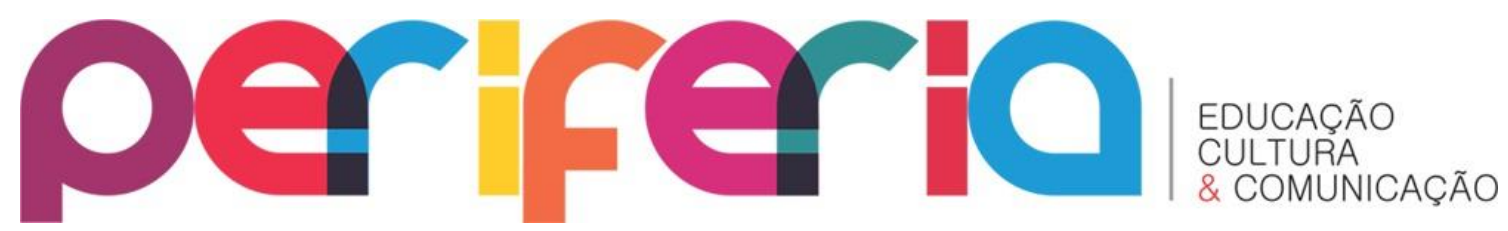

ISSN:1984-9540

DOI: $10.12957 /$ periferia.2021.28970

ÁVILA, G.; SALLÁN, J. La atención a las personas con discapacidad en las universidades mexicanas y españolas, desde la revisión de las políticas educativas. Educación, Madrid, n. 49, v. 25, p. 83-102, 2016.

BARDIN, L. Análise de Conteúdo. Portugal: Edições 70; LDA, 2010.

BRASIL. Associação Brasileira de Normas Técnicas. NBR 9050. Acessibilidade a edificações, mobiliário, espaços e equipamentos urbanos. Rio de Janeiro: ABNT, 2015.

CAMARGO, E.; NARDI, R. Contextos comunicacionales adecuados e inadecuados para la inclusión de alumnos con discapacidad visual en clases de física moderna. Enseñanza de las Ciencias, Barcelona, v. 31, n. 3, p. 155-175, 2013.

CAMARGO, E. Saberes docentes para a inclusão do aluno com deficiência visual em aulas de física. São Paulo: Editora Unesp, 2012.

COHEN, L.; MANION, L.; MORRISON, K. Research Methods in Education. New York: Routledge, 2011.

DINIZ, D.; BARBOSA, L.; SANTOS, W. Discapacidad, Derechos Humanos y Justicia. Sur, São Paulo, v. 6, n. 11, p. 65-77, 2009.

ESTÁCIO, M.; ALMEIDA, D. Pessoas com deficiência no Ensino Superior. Journal of Research in Special Educational Needs, New York, v. 16, n. 1, p. 836-840, 2016.

FUENTES, A. Integración escolar de alunos con deficiencia visual en España: algunas sugerencias espaciales y contribuciones tecnológicas y

tiflotecnologicas. Estudios Pedagógicos, Valdivia, n. 29, p. 143-153, 2003.

GROSS, M. Prácticas inclusivas para la población estudiantil en condición de discapacidad visual en el entorno universitario. Alteridad, Revista de Educación, Quito, v. 9, n. 2, p. 108-117, 2014.

MAGALHÃES, R.; RUIZ, E. Estigma e currículo oculto. Revista Brasileira de Educação Especial, Marília, v. 17, p. 125-142, 2011.

MANZINI, E. Considerações sobre a entrevista para a pesquisa social em educação especial: um estudo sobre análise de dados. In: JESUS, D.; BAPTISTA, C.; VICTOR, S. Pesquisa e educação especial: mapeando produções. Vitória: UFES, 2006a. p. 361-386.

MANZINI, E. (Org.). Inclusão e acessibilidade. Marília: ABPEE, 2006b.

MANZINI, E.; CORRÊA, P (Org.). Avaliação de acessibilidade na educação infantil e no ensino superior. São Carlos: Marquezine \& Manzini; ABPEE, 2014. 


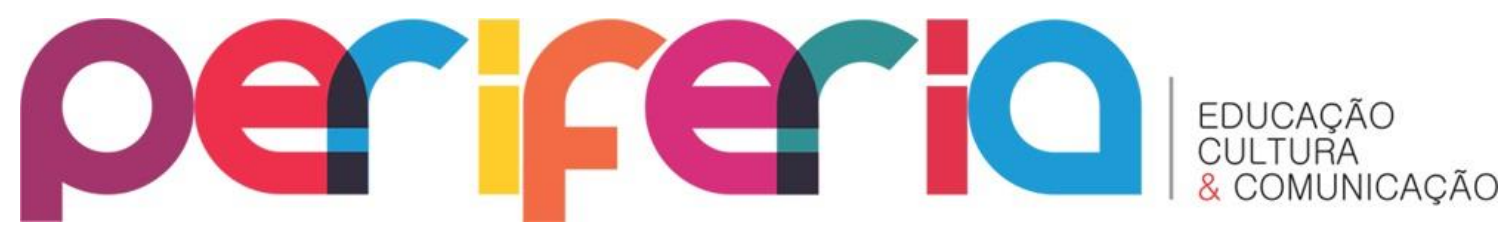

ISSN:1984-9540

DOI: $10.12957 /$ periferia. 2021.28970

MENDES, H.; BASTOS, C. Um estudo sobre a realidade da inclusão de pessoas com deficiência na educação superior no Paraná. Revista Educação Especial, Santa Maria, v. 29, n. 54, p. 189-202, 2016.

MERRIAM, S.; TISDELL, E. Qualitative Research: $A$ guide to design and implementation. Fourth Edition. New York: Jossey-Bass, 2015.

MINEDU. Educación básica especial y educación inclusiva. Balances y perspectivas. Lima: Ministerio de Educación. Viceministerio de Gestión Pedagógica, 2012.

MINEIRO, J.; ALMEIDA, A.; LÉLIS, C. Cartazes urbanos acessíveis a pessoas cegas: proposta de um modelo de design para todos, baseado numa solução mobile. Revista Brasileira de Design da Informação, São Paulo, v. 12, n. 1, p. 143-156, 2015.

MOTTA, L.; FILHO, P (Org.). Audiodescrição. Transformando Imagens em Palavras. São Paulo: Secretaria dos Direitos da Pessoa com Deficiência do Estado de São Paulo, 2010.

ONCE. Libro blanco para el diseño de la Tecnología. Móvil accesible y fácil de usar. Madrid: Organización Nacional de Ciegos Españoles, 2011.

PASTOR, C. Educación Superior Sin Barreras: La accesibilidad de las universidades para los estudiantes con discapacidad. Encounters on Education, Madrid, v. 6, p. 43-60, 2005.

PÉREZ-JORGE, D. et al. La identificación del conocimiento y actitudes del profesorado hacia inclusión de los alumnos con necesidades educativas especiales. European Scientific Journal, Lisboa, v. 12, n. 7, p. 64-81, 2016.

PEREIRA, M. Inclusão no ensino superior: trajetórias acadêmicas dos alunos com deficiência que entraram na Universidade Estadual do Rio Grande do Sul pelo sistema de cotas. Revista Educação Especial, Santa Maria, n. 32, p. 163174, 2008.

PEREIRA, R. et al. Inclusão de estudantes com deficiência no ensino superior: uma revisão sistemática. Revista Educação Especial, Santa Maria, v. 29, n. 54, p. 147-160, 2016.

RAMÍREZ, G. Los estudiantes universitarios con diversidad funcional visual. Sus retos. Revista Iberoamericana de Educación Superior, Ciudad de México, v. 6, n. 17, p. 135-158, 2015.

REGIANI, A.; MÓL, G. Inclusão de uma aluna cega em um curso de Licenciatura em Química. Ciência \& Educação, Bauru, v. 19, n. 1, p. 123-134, 2013. 


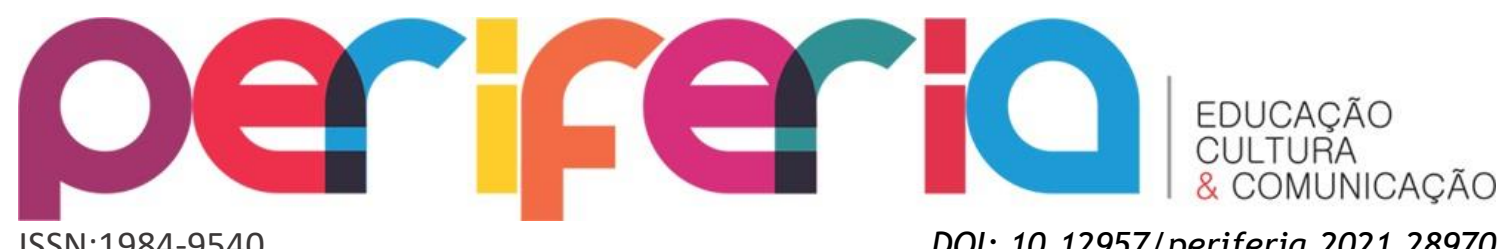

RIOS, G. et al. Audiodescrição e inclusão na educação a distancia: experiência do Núcleo de Educação a Distancia da UNESP. Journal of Research in Special Educational Needs, New York, v. 16, n. 1, p. 236-240, 2016 a.

RIOS, G. et al. Cultura inclusiva na educação a distancia: concepção de cursos acessíveis. Journal of Research in Special Educational Needs, New York, v. 16, n. 1, p. 332-335, 2016b.

ROCHA, T.; MIRANDA, T. Acesso a permanência do aluno com deficiência na instituição de ensino superior. Revista Educação Especial, Santa Maria, v. 22, n. 34, p. 197-212, 2009.

SALAZAR, D.; SÁNCHEZ, A. Aproximaciones a la inclusión del estudiante invidente en el aula de lengua extranjera en la Universidad del Valle. Lenguaje, Cali, v. 36, n. 1, p. 301-334, 2011.

SALLÁN, J.; MORENO, J. La acción tutorial en los estudiantes universitarios con discapacidad. Educación, Madrid, v. 22, n. 43, p. 71-90, 2013.

STUPP, R. Universidades Accesibles para Todos. In: JIMÉNEZ, S (ed.). Las personas con discapacidad en la educación superior. Una propuesta para la diversidad y la igualdad. San José: Fundación Justicia y Género, 2002. p. 1834.

URQUHART, C. Grounded theory for qualitative research: a practical guide. New York: SAGE Publications Ltd, 2012.

VIVEIROS, E.; CAMARGO, E. Teoria dos campos conceituais e neurociência cognitiva: utilizando uma interface cérebro-computador no ensino de física para deficientes visuais e físicos. Interciência e Sociedade, Mogi Guaçu, v. 3, p. 99-107, 2014.

YUE-TING, S.; MORASH, V. Teachers of students with visual impairments and their use of assistive technology: measuring the proficiency of teachers and their identification with a community of practice. Journal of Visual Impairment \& Blindness, New York, v. 108, n. 5, p. 384-398, 2014.

ZHOU, L. et al. Assistive technology competencies of teachers of students with visual impairments: a comparison of perceptions. Journal of Visual Impairment \& Blindness, New York, v. 105, n. 9, p. 533-547, 2011. 